\title{
Retrieval Processes Supporting Judgments of Recency
}

\author{
Kerrie L. Grove and Edward L. Wilding
}

\begin{abstract}
The circumstances under which different retrieval processes can support judgments about how long ago events occurred remain a matter of debate, as do the ways in which retrieved information can be employed in support of such judgments. In order to contribute to an understanding of the nature and number of distinct retrieval processes that support time judgments, event-related potentials (ERPs) were acquired during a continuous verbal memory task, where the lag between presentation and re-presentation of words was varied. Participants made judgments of recency (JORs), indicating the number of words that had intervened between presentation
\end{abstract}

\section{INTRODUCTION}

Retrieval from episodic memory is considered to entail recovery of spatio-temporal information (Tulving, 1983, 2002). The focus in this article is on temporal information, and on how judgments about when events occurred are made. Although judgments of this kind (often termed judgments of recency: JORs) are mainly considered in the same way as other kinds of episodic judgments, the ways in which recovered information is employed in service of temporal judgments is likely not to be entirely equivalent to the ways in which other episodic decisions are made. This distinction can be seen in some theories of memory for time, and in one careful consideration, Friedman (1993) described a key distinction between location-based and distance-based processes. Judgments associated with location-based processes rely on recovery of contextual and often factual information that will permit an event to be located accurately in time. Judgments associated with distance-based processes are assumed to involve an assessment of memory strength, with "strong" memories being judged as having occurred more recently than "weak" memories (see also Friedman, 1996, 2001).

The foregoing description for location-based processes links it with the process of recollection, which involves recovery of qualitative information about a prior encounter, and which might permit an event to be located accurately in time (Yonelinas, 2002; Jacoby \& Kelley, 1992; Jacoby \& Dallas, 1981). Recollection can also be employed as a distance-based process, however.

Cardiff University, Cardiff, Wales, UK and re-presentation. Two spatially and temporally separable ERP effects predicted JORs, and the two effects bore correspondences with ERP modulations that have been linked to the processes of recollection and familiarity, suggesting that both of these processes contributed to JORs. The two effects predicting recency judgments also did so in the same way, with larger effects uniformly predicting shorter lag judgments. In so far as the sizes of the effects index memory strength, these findings are consistent with theoretical accounts of JORs where strength is employed heuristically: The more information recovered, the more recently the event occurred.
According to this argument, qualitative information about an event can be recovered, but that information may be diagnostic for a temporal judgment only in a quantitative sense: Some combination of the amount of qualitative information recovered and the strengths of these memories may be used as the basis for judging how recently an event occurred (Friedman, 1993, 1996, 2001; Brown, Rips, \& Shevell, 1985; Wells, 1974).

Another process that can be considered a distancebased means of making JORs is familiarity. This process is widely thought to provide a graded index of memory strength (Yonelinas, 2002), and as such, can presumably be one distance-based means of making judgments about when events occurred: The more familiar an item, the more recently it was encountered (Curran \& Friedman, 2003). The ways in which recollection and/or familiarity might support judgments for time are investigated in the experiment that is described in this article, using a variant of a paradigm that has been employed in a number of behavioral experiments.

In a series of studies, Hintzman (2001, 2003, 2005) has investigated the processes that support judgments of when events occurred, using a continuous recognition memory task employed previously by Hinrichs (1970) and Hinrichs and Buschke (1968). In the typical incarnation of this task, stimuli are repeated after different numbers of intervening items (lags). Participants are asked to make initial old/new judgments, followed by, for items judged to be old, a JOR, indicating how many items intervened between the first and second presentations.

In a representative experiment, the test stimuli were equal numbers of high and low frequency words, and 
were repeated after lags of between 5 and 30 intervening words (Experiment 1; Hintzman, 2003). At every lag, the mean JOR was shorter for low-frequency than for highfrequency words. Consistently shorter lag judgments for one stimulus class than for another have been obtained in other circumstances as well: Long durations of study presentation $(3500 \mathrm{msec})$ attract shorter lag judgments than do short presentation durations (1500 msec; Hintzman, 2005), and this is also true for concrete versus abstract words (Hintzman, 2003), as well as for pictures versus words (Hintzman, 2005). Across these experiments, the lags extended from 5 to 60 intervening stimuli.

Hintzman $(2003,2004,2005)$ has argued that the reason for the consistently shorter lag judgments for one stimulus class than for the other is that the class attracting shorter lag judgments is the one that elicits "stronger" memories, and memory strength is the metric employed for the lag judgments. This argument links JORs in this task format to distance-based rather than location-based processes (Friedman, 1993). It has been proposed, moreover, that location-based processes are unlikely to support JORs in tasks of this type because of the lack of "landmarks" that would appear to be necessary for locationbased judgments (Hintzman, 2005; Hinrichs, 1970).

Assuming that this account is correct, a question that follows is whether recollection as well as familiarity might support recency judgments in tasks of this type. One approach to addressing these issues is to collect measures of recollection and familiarity alongside JORs. In this vein, Hintzman (2001) asked participants to make remember/know judgments to each test item after their old/new recognition judgment and before making their JOR. At short lags ( $<40$ intervening items), the most accurate lag judgments were for items attracting remember responses, whereas at longer lags (up to 80 intervening items) the most accurate judgments were for items associated with know responses. This pattern of data is broadly consistent with the view that both recollection and familiarity contribute in some form to JORs, although experiments in which multiple memory measures are taken are vulnerable to criticism on the grounds that the requirement to make one kind of judgment influences the other judgment.

For example, one explanation for Hintzman's findings is that participants are likely to give a remember response for items where they are confident in their lag judgment, perhaps because they assume that accurate lag responses will be based upon remembering. This possibility cannot be ruled out in tasks where both lag and subjective memory judgments are made (for a discussion, see Hintzman, 2001). A second consideration is that simply an association between lag and recollection-as indexed by remember judgments - does not provide a basis for determining with any degree of confidence whether recollection supported lag judgments in a distance- or a location-based manner. In so far as a proportion of items attracting remember judgments are also familiar, more- over (Yonelinas \& Jacoby, 1995), then the behavioral data described here remain ambiguous with respect to which processes associated with remember and know responses do, in fact, support recency judgments.

A complementary means of providing data germane to the question of the processes supporting JORs is to acquire event-related potentials (ERPs) alongside behavioral measures, and analyze ERP old/new effects in order to shed light on the processes that are engaged during recency tasks. ERP old/new effects are differences between the ERPs elicited by old and new test items that attract correct judgments (Rugg, 1994). There are several old/new effects, two of which are the mid-frontal and left parietal ERP effects. These have been linked with the processes of familiarity and recollection, respectively (for reviews, see Curran, Tepe, \& Piatt, 2006; Rugg, 2004; Wilding \& Sharpe, 2003; Friedman \& Johnson, 2000).

The mid-frontal ERP old/new effect-also referred to as the FN400 (Curran, 1999)-comprises a greater relative positivity for old than for new test items to which correct recognition memory judgments are made (for review, see Curran, Tepe, et al., 2006). The effect is evident at frontal electrodes from 300 to 500 msec poststimulus, and evidence supporting the link between this effect and familiarity has come from studies showing that a greater positivity relative to that elicited by new items is shared by old judgments to two critical classes of test items: copy cues of studied items, and "similar lures" that are related closely to studied items along some dimension (Curran \& Cleary, 2003; Curran, Tanaka, \& Weiskopf, 2002; Nessler, Mecklinger, \& Penney, 2001; Penney, Mecklinger, \& Nessler, 2001; Curran, 2000). In so far as old (incorrect) responses to similar lures are made on the basis of familiarity (Hintzman, Caulton, \& Levitin, 1998; Hintzman \& Curran, 1994), these data points are consistent with the view that this is the process that the mid-frontal ERP old/new effect indexes.

The findings in two recent ERP studies of recognition memory are also particularly important here. First, Woodruff, Hyama, and Rugg (2006) showed that the mid-frontal ERP old/new effect increases in magnitude along with the level of confidence rating that accompanies a recognition memory decision. Second, the midfrontal ERP old/new effect is sensitive to changes in criterion placement (Azimian-Faridani \& Wilding, 2006; also see Bridson, Fraser, Herron, \& Wilding, 2006; Curran, 2004). These factors are both ones that have been associated with the process of familiarity to a greater degree than they are associated with recollection (for a review, see Yonelinas, 2002). In combination, these findings suggest that the mid-frontal ERP old/new effect indexes the process of familiarity in a graded manner, thereby making it a candidate for a process that might support distance-based judgments of time.

The left parietal ERP old/new effect also takes the form of a greater relative positivity for old than for new test items to which correct judgments are made. The effect is 
evident typically from 500 to $800 \mathrm{msec}$ poststimulus, and for verbal stimuli is largest at posterior scalp locations, with a bias toward the left hemisphere (Rugg, 1994). The amplitude of this effect is attenuated markedly in people who have memory deficits that are restricted primarily to recollection (Duzel, Vargha-Khadem, Heinze, \& Mishkin, 2001; Mecklinger, 2000; Tendolkar et al., 1999; Mecklinger, von Cramon, \& Matthes-von Cramon, 1998; Smith \& Halgren, 1989). In addition, the amplitude of the effect varies according to the amount or quality of contextual information that is retrieved (Duzel, Yonelinas, Mangun, Heinze, \& Tulving, 1997; Smith, 1993; in particular, see Vilberg, Moosavi, \& Rugg, 2006; Wilding, 2000; Wilding \& Rugg, 1996).

How can these ERP indices be employed in order to assess the contributions that recollection and familiarity make to JORs? If recollection and familiarity are employed as distance-based processes, then the magnitudes of the left parietal and the mid-frontal ERP old/ new effects will be correlated inversely with lag judgments. This prediction is based on the assumption that larger old/new effects signal recovery of more taskrelevant information (Woodruff et al., 2006; Wilding, 2000), and that the volume of information that is recovered is employed as an index of relative recency. If familiarity alone contributes to lag judgments on this task, then modulations of the electrical record that predict lag judgments will be restricted to the midfrontal ERP old/new effect. The same logic applies to modulations of the left parietal ERP old/new effect, and at issue in this experiment is the ways in which two classes of retrieval process, in isolation or in combination, support judgments for when events occurred.

\section{METHODS}

\section{Participants}

There were 42 participants (12 men) aged between 18 and 24 years (mean age $=20$ years). All were righthanded and reported normal or corrected-to-normal vision. All participants were undergraduates at Cardiff University, and were paid $£ 7.50 / \mathrm{hr}$. They all reported speaking English as their native language, and no participants reported taking psychotropic medication or having a diagnosis of dyslexia. All gave informed consent prior to the experiment. The datasets from 36 participants (9 men) were included in the initial analyses described below. Three participants did not complete the entire experiment due to technical problems, and for the remaining three, there were insufficient trials in critical conditions after artefact rejection (see below).

\section{Materials and Design}

Stimuli were 235 low-frequency words taken from the MRC Psycholinguistic database (4-9 letters, Kucera-
Francis written frequency 1-7 per million, imageability rating 500-700, concreteness rating 500-600; www.psy. uwa.edu.au/MRCDataBase/uwa_mrc.htm). Each complete task list comprised two blocks. Each block contained 109 words, 90 of which were repeated, with an equal number (30) after 5, 15, and 25 intervening words The order of re-presentation of words at each lag was determined pseudorandomly for each block. The 19 words in each block that were not repeated were presented toward the end of each block, ensuring that words repeated at each lag were distributed relatively evenly throughout blocks. Five further lists were created from the initial list, such that across lists all items were encountered at each lag, and each block within each list occurred at the start of the list. A further 17 words, 13 of which were repeated, were used in an initial practice block. In total, participants saw 428 stimuli (199 per block, 30 in the practice phase). All stimuli were presented on a computer monitor located $1 \mathrm{~m}$ away from participants. They were presented in uppercase white letters, set against a black background, and subtended maximum visual angles of $0.6^{\circ}$ (vertical) and $5^{\circ}$ (horizontal).

\section{Procedure}

Participants were fitted with an elasticated electrode cap prior to the experiment (see below). They were seated in a sound-attenuated booth facing a monitor with their hands resting on a keypad. They read through an instruction sheet and the instructions were then relayed verbally. Each experiment block began with a "ready" signal, lasting $5000 \mathrm{msec}$. Each trial began with a fixation mark (*). This was visible for $500 \mathrm{msec}$ and was followed by a blank screen (100 msec). Words were then presented for $300 \mathrm{msec}$, followed by a blank screen during which participants indicated whether the word was old or new via keypress using left and right thumbs. The screen was blanked for $1000 \mathrm{msec}$ after the response and then the words "How Far Back?" were shown. Participants were instructed that, if they had indicated a word to be new, then pressing any key would initiate the next trial. For words judged to be old, they were instructed to indicate whether the word had been represented after 5, 15, or 25 intervening words. The three JOR options were made via three key buttons on one hand, with lag 5, 15, and 25 judgments made with the index, middle, and fourth fingers, respectively. This response was followed by a 500-msec blank screen before the next trial commenced. An equal number of participants completed each task list, and an equal number completed the experiment for the four possible combinations of left/right hand responses for the old/new judgment and the second response. There was a break of approximately 5 min between blocks. Participants were asked to balance speed and accuracy equally, and each test block took, on average, 18 min to complete. 
Table 1. Probabilities of Correct Old and New Judgments and Associated Reaction Times (RT), Separated According to Lag $(n=36)^{\mathrm{a}}$

\begin{tabular}{lcccc}
\hline & New & Lag 5 & Lag 15 & Lag 25 \\
\hline$p$ (correct) & $.95(.05)$ & $.88(.10)$ & $.85(.12)$ & $.83(.13)$ \\
RT (msec) & $841(204)$ & $961(242)$ & $925(211)$ & $906(203)$ \\
\hline
\end{tabular}

${ }^{\mathrm{a}} \mathrm{Standard}$ deviations are in parentheses.

\section{Electrophysiological Recording Procedure}

The electroencephalogram (EEG) was recorded from 25 silver/silver chloride electrodes housed in an elastic cap. The locations of the electrode montage correspond approximately to the following 10-20 locations: $\mathrm{Fz}, \mathrm{Cz}$, Pz, Fp1/Fp2, F3/F4, F5/F6, F7/F8, C3/C4, C5/C6, T7/T8, P3/P4, P5/P6, P7/P8, O1/O2 (Jasper, 1958). Additional electrodes were placed on the left and right mastoids. Electrooculogram (EOG) readings were recorded from above and below the right eye (VEOG) and from the outer canthi (HEOG). Trials containing large EOG artifacts were rejected, as were trials containing A/D saturation or baseline drift (difference between first and last data points) exceeding $\pm 80 \mu \mathrm{V}$. Other EOG blink artifacts were corrected using a linear regression estimate (Semlitsch, Anderer, Schuster, \& Presslich, 1986). EEG was recorded continuously at $200 \mathrm{~Hz}$ with Fz as the reference electrode, and was re-referenced computationally off-line to the algebraic mean of the signal at the mastoids into baseline corrected epochs of $1000 \mathrm{msec}$ (200 data points), each including a $100-\mathrm{msec}$ prestimulus baseline. The data from $\mathrm{Fz}$ were reclaimed. EEG and EOG were recorded with a bandwidth of $0.03-40 \mathrm{~Hz}$ $(-3 \mathrm{~dB})$. Participants were excluded from analyses if they did not contribute at least 12 trials after artifact rejection to the categories of interest. The averaged ERPs underwent a 7-point binomially weighted smoothing filter prior to analysis (see Wastell, 1979), and mean amplitudes for selected time windows were extracted via dedicated in-house software.

\section{RESULTS}

\section{Behavioral Data}

Table 1 shows the probabilities of correct old/new judgments to new words and to old words separated according to lag. Also shown in the table are the RTs for these classes of response. Old/new discrimination ( $p$ [hit] $p$ [false alarm]) was reliably greater than chance at each lag $[t(35)>30.00, p<.001$ in each case]. A one-way ANOVA $^{1}$ contrasting these three discrimination measures revealed a main effect $[F(1.77,62.10)=8.56, p<$ $.01]$, and follow-up paired $t$ tests revealed that old/new discrimination decreased with increasing lag $[t(35)>$ 2.00, $p<.05$ for each contrast]. A one-way ANOVA on the RT categories for which the means are shown in Table 1 also revealed reliable differences across the categories $[F(1.86,65.13)=7.03, p<.001]$. Although not differing reliably from each other, RTs for all classes of hit were slower than RTs for correct rejections $[t(35)>$ $3.00, p<.01$ in each case].

Table 2 shows the probabilities of each lag judgment at each lag for words judged correctly to be old. The bold values on the diagonal are the probabilities of a correct lag judgment. For each lag, the likelihood of a correct lag judgment was above chance $[t(35)>7.00, p<.001]$. Paired contrasts between the likelihoods of a correct response at each lag revealed only that correct lag 15 judgments were made more often than correct lag 25 judgments $[t(35)=3.47, p<.01]$, although the advantage for lag 5 over lag 25 judgments approached significance $(p=.06)$. The mean RTs for items attracting correct lag judgments were 924, 923, and $946 \mathrm{msec}$ for lags 5, 15, and 25, respectively. A one-way ANOVA on these RTs revealed no significant differences according to lag.

\section{ERP Data}

The analysis strategy for the ERP data was guided by previous findings regarding the time courses and scalp locations of modulations that index memory processes. The data were analyzed for the 300-500 and 500800 msec epochs, including data from 10 electrodes, an equal number at anterior (F5, F3, Fz, F4, F6) and posterior ( $\mathrm{P} 5, \mathrm{P} 3, \mathrm{Pz}, \mathrm{P} 4, \mathrm{P} 6)$ scalp sites. The findings in previous studies indicate that the old/new effects in these two epochs have scalp distributions which vary along the anterior-posterior as well as the lateral dimension and, in addition, index functionally distinct processes (Curran, Tepe, et al., 2006; Allan, Wilding, \& Rugg, 1998). This montage of electrodes is sufficiently broad to capture the key effects identified previously, and also encompasses the distributions of the effects of interest that were obtained in this experiment.

Figure 1 supports this claim and shows the ERP old/ new effects for items attracting correct lag judgments (separated according to lag) for a subset of the sites encompassing the spatial extent of the electrodes included

Table 2. Probabilities of Each Lag Judgment (Lag 5, 15, 25) Conditional on a Correct Old Judgment and Separated According to Lag $(n=36)^{\text {a }}$

\begin{tabular}{lccc}
\hline & \multicolumn{3}{c}{ Actual Lag } \\
\cline { 2 - 4 } Judgment & Lag 5 & Lag 15 & Lag 25 \\
\hline Lag 5 & $\mathbf{. 5 7 ( . 1 5 )}$ & $.14(.09)$ & $.06(.04)$ \\
Lag 15 & $.36(.13)$ & $\mathbf{. 6 0 ( . 1 1 )}$ & $.45(.12)$ \\
Lag 25 & $.07(.05)$ & $.26(.12)$ & $\mathbf{. 4 8}(. \mathbf{1 4})$ \\
\hline
\end{tabular}

${ }^{\mathrm{a}}$ Correct lag judgments are in bold, standard deviations are in parentheses. 


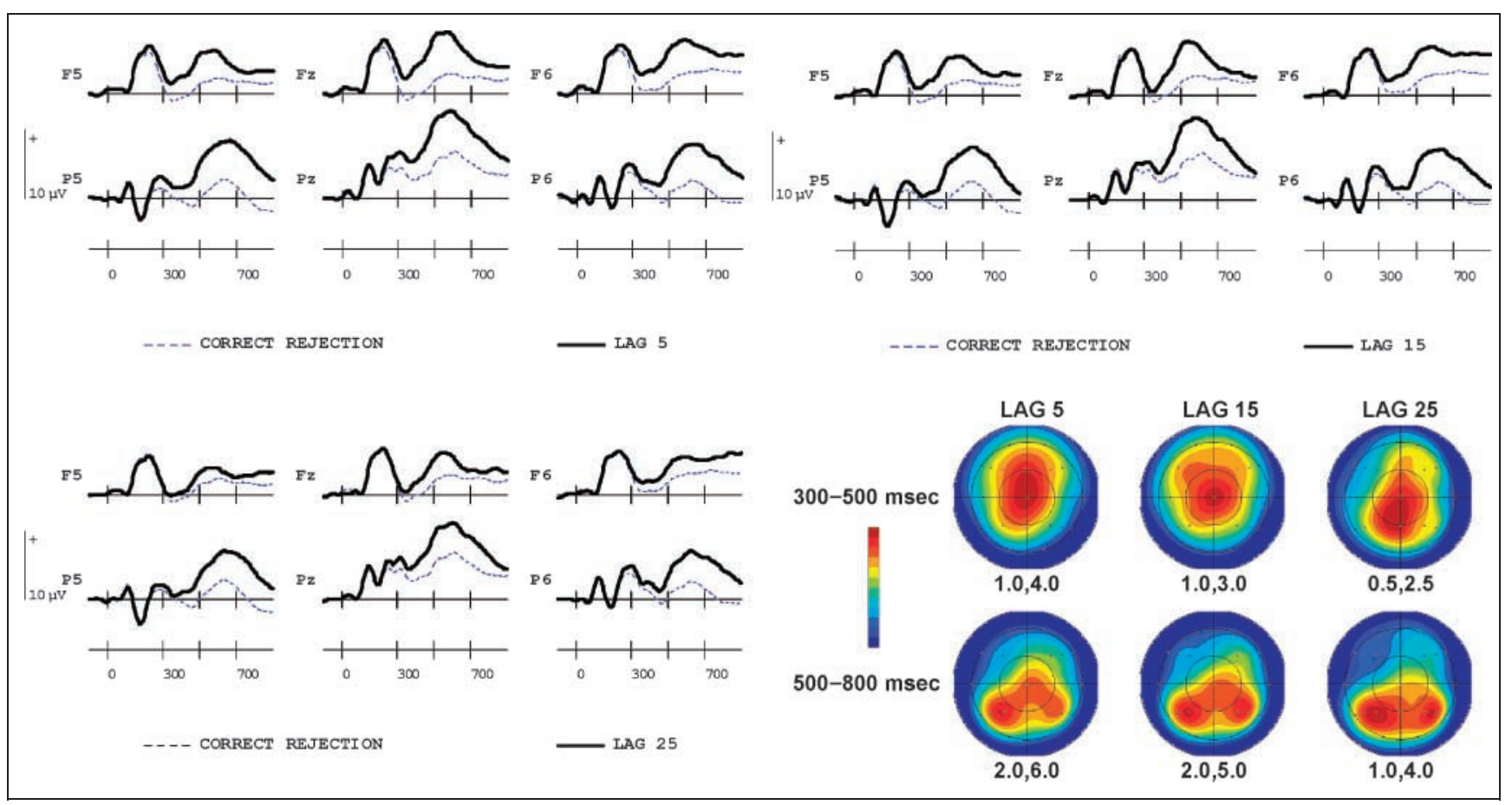

Figure 1. Grand-average ERPs associated with correct rejections and with lag 5, 15, and 25 items attracting correct lag judgments. For each lag, the ERPs are shown for three frontal (F5, Fz, F6) and three parietal (P5, Pz, P6) electrodes. Lower right panel: Topographic maps showing the scalp distributions of the old/new effects associated with correct lag judgments for the 300-500 and 500-800 msec time windows. The maps were calculated on difference scores obtained by subtracting mean amplitudes within each time window for correct rejections from amplitudes associated with correct lag 5, 15, and 25 judgments, respectively.

in the analyses described below. The lower right panel of Figure 1 shows the scalp distributions of the neural activity that differentiates items attracting correct lag judgments from correct judgments to new items at each lag for the 300-500 and 500-800 msec epochs. For each epoch and contrast, the amplitudes are scaled over the color range according to the maximum and minimum amplitude values that were obtained, and these values are shown directly below each scalp map. Figure 1 shows that the scalp distributions of the ERP old/new effects in the 500-800 msec epoch differ primarily in magnitude, with the effects decreasing in magnitude with increasing lag. For the earlier (300-500 msec) epoch, the maxima of the scalp distributions of the ERP old/new effects move posteriorly with increasing lag. The principal reason for this shift is the progressive attenuation of the ERP old/new effects at anterior sites with increasing lag, alongside a less pronounced degree of attenuation at posterior scalp locations.

The first contrast comprised a global analysis of the ERP old/new effects for items attracting correct lag judgments. This initial ANOVA included the factors of response category (4 levels: correct rejections and correct lag judgments at each lag), epoch (2 levels: 300-500 and 500-800 msec), the anterior-posterior (AP) dimension ( 2 levels: anterior and posterior), and site ( 5 levels: left-hemisphere inferior and superior, midline and righthemisphere inferior and superior sites). No comment is made below on main effects and interactions that do not involve the factor of response category. The mean number of trials (range in parentheses) contributing to the correct rejection ERP response category was 179 (121204). The corresponding values for correct lag 5, 15, and 25 judgments were 26 (12-30), 28 (12-41), and 21 (1237), respectively.

The initial ANOVA revealed a main effect of response category $[F(2.8,98.4)=40.25, p<.001]$, as well as two-, three-, and four-way interactions involving this factor [Category $\times$ Epoch: $F(2.4,83.4)=10.99, p<$ .01 ; Category $\times$ AP: $F(2.8,99.1)=4.21, p<.01$; Category $\times$ Epoch $\times$ AP: $F(2.5,88.5)=18.30, p<.001$; Category $\times$ Epoch $\times$ Site: $F(5.2,180.8)=5.17, p<.001$; Category $\times$ Epoch $\times \mathrm{AP} \times$ Site: $F(2.8,98.5)=3.12, p<$ $.05]$. The first follow-up tests that were conducted in order to determine the reason for the four-way interaction term comprised analyses of the ERP old/new effects separately for each lag, and the outcomes of these analyses in Table 3 show all of the reliable effects involving category that were obtained.

The table shows that there are reliable old/new effects in each epoch and at each lag. For the 300-500 msec epoch, the interactions between category and site reflect the fact that, at each lag, the magnitude of the positivegoing old/new effects falls off with distance from the midline. The interaction between these two factors and the AP dimension for the lag 5 old/new effect reflects the central midline maximum of the effect. For the 500800 msec epoch, the interactions between category and 
Table 3. The Outcomes of the Analyses ( $F$ Values and Significance Levels) of the ERP Old/New Effects for Words Attracting Correct Old/New and Correct Lag Judgments for the 300-500 and 500-800 msec Epochs ${ }^{\mathrm{a}}$

\begin{tabular}{|c|c|c|c|c|c|c|}
\hline & \multicolumn{3}{|c|}{$300-500 \mathrm{msec}$} & \multicolumn{3}{|c|}{$500-800 \mathrm{msec}$} \\
\hline & $\operatorname{Lag} 5$ & $\operatorname{Lag} 15$ & $\operatorname{Lag} 25$ & $\operatorname{Lag} 5$ & $\operatorname{Lag} 15$ & $\operatorname{Lag} 25$ \\
\hline CC $(1,35)$ & $66.62 * * * *$ & $68.10 * * * *$ & $25.68 * * * *$ & 82.90 ***** & $67.06^{* * * * *}$ & $43.59 * * * *$ \\
\hline $\mathrm{CC} \times \mathrm{AP}(1,35)$ & $3.04 *$ & - & - & $14.38^{* * *}$ & $14.47 * * *$ & $16.98 * * * *$ \\
\hline $\mathrm{CC} \times \mathrm{ST}(4,140)$ & $15.23 * * * *(.61)$ & $4.90 * * *(.57)$ & $3.56 * *(.46)$ & - & - & - \\
\hline $\mathrm{CC} \times \mathrm{AP} \times \mathrm{ST}(4,140)$ & $3.28 * *(.83)$ & - & $2.52 *(.69)$ & $6.43 * *(.46)$ & - & $2.82 *(.48)$ \\
\hline
\end{tabular}

Full degrees of freedom are shown on LHS, with epsilon values in parentheses.

${ }^{\mathrm{a} T h e}$ factors are response category (CC), anterior-posterior dimension (AP), and site (ST).

$* p<.1$.

$* * p<.05$.

$* * * p<.01$.

$* * * * p<.001$

the AP dimension reflect the posterior maxima of the ERP old/new effects in this time window, with the threeway interaction revealed in the lag 5 analysis reflecting the left posterior maximum of the old/new effect.

The important question for the pre-experimental hypotheses is how the ERP old/new effects change according to epoch and lag. This was assessed first by an analysis involving the old/new effects (hits - correct rejections: 3 levels) at each lag, as well as all other factors included in the initial global analysis. The main effect of epoch $[F(1,35)=56.20, p<.001]$ was moderated by an interaction between epoch and the AP dimension $[F(1,35)=6.09, p<.05]$, as well as epoch, the AP dimension, and site $[F(1.6,55.2)=7.62$, $p<.001]$. These outcomes reflect the change in the scalp distributions of the old/new effects over time, with the shift to a somewhat more left-sided and posterior scalp distribution in the later epoch, mirroring the findings in previous reports. This claim was confirmed by the fact that these interaction terms survived when the same analysis was conducted on data rescaled using the max-min method (McCarthy \& Wood, 1985) in order to avoid confounding changes in the shapes of distributions with changes in amplitudes [Epoch $\times$ AP: $F(1,35)=31.33, p<.001$; Epoch $\times$ AP $\times$ Site: $F(2.0$, $69.2)=4.35, p<.05]$.

Figure 1 also suggests that the changes in the old/new effects with increasing lag are more pronounced at anterior than at posterior electrodes in the 300-500 msec epoch, whereas they are more widespread in the later epoch. This was not confirmed in the outcomes of the ANOVA, however, where the main effect of category $[F(1.9,66.6)=7.70, p<.01]$ was not moderated by higher-order interactions involving epoch, although the Epoch $\times$ Category $\times$ Site interaction approached significance $[F(3.2,111.0)=2.16, p=.09]$. Although the outcomes of these analyses do not permit strong claims that the effects of lag were restricted to the scalp lo- cations at which the old/new effect was largest, the fact that these initial analyses were restricted to items at each lag that attracted correct lag judgments means that they cannot distinguish between modulations that vary with lag, and those that predict JORs.

In a critical second stage of analyses, therefore, contrasts were made between the old/new effects for items from the same lag that attracted either correct or incorrect lag judgments. These analyses were restricted to data from a subset of 23 participants who made sufficient correct and lag 15 (incorrect) responses to lag 5 as well as lag 25 items to permit formation of reliable averaged ERPs for all four of these response categories. The mean number of trials contributing to the ERP correct rejection response category for this subset was 190 (range $=154-204)$. The corresponding values for correct lag judgments to lag 5 and 25 items were 27 (1235 ) and 23 (12-37), whereas the values for incorrect (lag 15) judgments to lag 5 and lag 25 items were 18 (12-35) and 22 (12-40). Appendices 1 and 2 show the behavioral data for this subset of 23 participants, whereas Appendix 3 shows the outcomes of the analyses of the ERP old/new effects for items attracting correct judgments at each lag. There is considerable overlap between the outcomes for this subset and those for the full set of 36 participants that are shown in Table 3.

In an initial analysis on the data from this subset of participants, the ERPs elicited by lag 5 and lag 25 items attracting incorrect (lag 15) recency judgments were contrasted with lag 15 items attracting correct judgments. The analyses were conducted using the 10 electrode montage employed in the ANOVAs described previously, with factors of epoch, the AP dimension, and site. No reliable effects involving response category were revealed.

In order to determine further how the ERPs elicited by items judged correctly to be old varied according to the accuracy of lag judgments, mean amplitude measures for the ERP old/new effects associated with correct and 
incorrect lag judgments at lag 5 and lag 25 were submitted to ANOVA, including the factors of lag (5 vs. 25), accuracy (correct vs. incorrect), and epoch (300-500 vs. $500-800 \mathrm{msec}$ ). The analyses included the data from the 10 anterior and posterior scalp locations employed in the analyses described above, split according to the AP dimension as well as site. The initial global analysis revealed that the main effects of epoch $[F(1,22)=$ $36.32, p<.001]$ and lag $[F(1,22)=16.67, p<.001]$ were moderated by an interaction between these factors in combination with the accuracy and the AP dimensions $[F(1,22)=4.55, p<.05]$. The five-way interaction involving the additional factor of site also approached significance $[F(2.6,57.2)=2.50, p=.08]$.

In light of the interaction terms involving epoch, separate analyses were conducted on the data for the 300-500 and 500-800 msec time windows. For the earlier period, the interaction between lag, accuracy, and the AP dimension was reliable $[F(1,22)=4.78, p<.05]$. Separate analyses at posterior and at anterior sites revealed that, although the ERPs elicited by lag 5 items were more positive-going than those elicited by lag 25 items over both scalp regions [main effects of lag: anterior: $F(1,22)=13.05, p<.01$; posterior: $F(1,22)=$ $10.43, p<.01]$, only at anterior locations did this effect interact with the accuracy of the judgments made to those items $[F(1,22)=5.36, p<.05]$. The reasons for this interaction term can be seen in the waveforms and scalp maps in Figure 2: Although the ERPs associated with correct lag judgments were more positive-going than those associated with incorrect lag judgments for lag 5 items, the reverse was true for lag 25 items. For both lags, greater relative positivity at anterior scalp locations predicts a shorter lag judgment. Paired contrasts restricted to anterior locations revealed that lag 15 judgments to lag 5 and lag 25 items did not differ reliably from each other, whereas both were reliably less positivegoing than a correct judgment to a lag 5 item [lag 5: $F(1$, $22)=5.50, p<.05$; lag 25: $F(1,22)=9.71, p<.01]$. Only lag 15 judgments to lag 5 items were reliably more positive-going than a correct lag 25 judgment $[F(1,22)=$ 5.92, $p<.05]$.

For the 500-800 msec epoch, the interaction between lag and accuracy was significant $[F(1,22)=4.29, p<$ $.05]$, but there was no three-way interaction involving the AP dimension $[F(1,22)=0.90, p>.3]$, contrasting with the findings in the preceding epoch. Figure 2 shows that the reason for the Lag by Accuracy interaction mirrors the reason for the same interaction term in the 300 500 msec epoch: Greater relative positivity predicts a

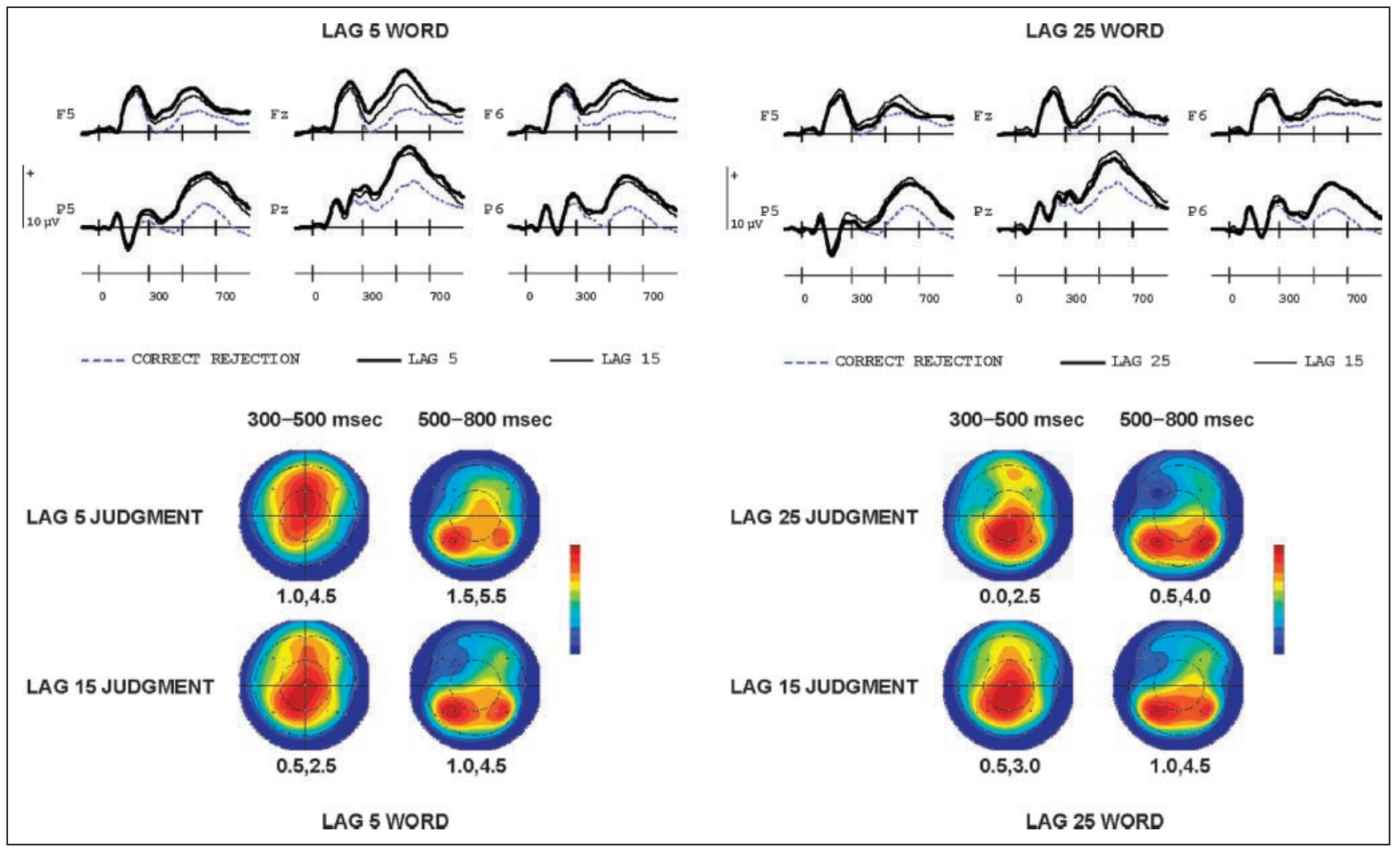

Figure 2. Grand-average ERPs associated with correct and incorrect JORs and correct rejections $(n=23)$. (Top) The left-hand side of the figure shows ERPs elicited by correct rejections, and by lag 5 items attracting correct or incorrect (lag 15) judgments. The right-hand side of the figure shows ERPs elicited by correct rejections, and lag 25 items attracting correct or incorrect (lag 15) judgments. (Bottom) Topographic maps showing the scalp distributions of the ERP old/new effects associated with correct and incorrect lag judgments for lag 5 items (left-hand side) and for lag 25 items (right-hand side). Maps derived as described in the legend for Figure 1. 
shorter lag judgment. Paired contrasts including data from anterior as well as posterior locations revealed that incorrect (lag 15) judgments to lag 5 and lag 25 items did not differ reliably from each other, whereas both were reliably less positive-going than a correct judgment to a lag 5 item $[\operatorname{lag} 5: F(1,22)=5.50, p<.05$; lag 25: $F(1$, 22) $=9.71, p<.01]$.

A final set of analyses was conducted on difference scores rescaled using the max-min method. For lag 5 items, the data submitted to rescaling were mean amplitudes associated with incorrect (lag 15) judgments subtracted from those associated with correct lag 5 judgments. For lag 25 items, the reverse subtraction was employed: Mean amplitudes associated with correct (lag 25) items were subtracted from those associated with incorrect (lag 15) judgments. The rescaled data were submitted to ANOVA with factors of epoch (300500 vs 500-800), lag (5 vs 25), the AP dimension (2 levels), and site ( 5 levels, as described previously). The interaction between epoch, the AP dimension, and site was reliable $[F(1.9,42.0)=3.41, p<.05]$, a finding consistent with the view that qualitatively different neural activity predicted lag judgments in the 300-500 and 500-800 msec epochs.

\section{DISCUSSION}

The ERP findings in this experiment support the view that two distinct processes are engaged when short-term JORs are made. The ERP data also license the claim that both processes can be characterized as distance-based means of making judgments about when events occurred. The key findings that support this claim are the ways in which ERP old/new effects change with lag, and more critically, the ways in which ERP old/new effects predict the accuracy of lag judgments. Following a brief summary of the behavioral data, these two components of the electrophysiological findings are addressed in turn.

$\mathrm{Old} / \mathrm{new}$ discrimination declined with increasing lag, as did the accuracy of JORs, a pattern of performance consistent with that obtained in previous comparable studies (Hintzman, 2004, 2005; Hinrichs \& Buschke, 1968). The fact that there is a greater overall likelihood of a lag 15 judgment (see Table 2) might be interpreted as a tendency to default to this response option when uncertain, but attributing aspects of the pattern of behavioral data to response bias is complicated by the fact that, for both lag 5 and lag 25 items, a lag 15 judgment is temporally closer to the correct response than the other incorrect alternative.

The initial focus in the analysis of the ERP data was on the old/new effects associated with correct lag judgments, and the sizes of these effects decreased as lag increased. Previous ERP studies where times between first and second presentations of items were varied have produced mixed results, and the reasons for some of the disparities remain to be resolved (see Wolk et al., 2006; Curran \&
Friedman, 2004; Nessler \& Mecklinger, 2003; Friedman, 1990a, 1990b; Rugg, 1990; Rugg \& Nagy, 1989). For present purposes, however, the first important result was the demonstration that topographically distinct ERP old/new effects were present in the 300-500 and 500-800 msec epochs. The scalp distributions of these ERP old/new effects correspond broadly with the effects reported previously in ERP studies of episodic retrieval, comprising a more posterior and left-lateralized distribution in the later than in the earlier epoch (cf. Azimian-Faridani \& Wilding, 2006; Curran, 1999, 2000; Wilding, 1999). These findings are consistent with the view that at least two distinct memory processes were engaged in the first 800 msec following stimulus presentation.

Figure 1 shows the distributions of these ERP old/ new effects, and how they change with lag. For the 300500 msec time window, the progressively posterior maximum of the old/new effects with increasing lag is consistent with the view that the amplitude of the midfrontal old/new effect - the putative index of familiaritybecame smaller as lag increased. Statistical evidence for this interpretation would have comprised reliable differences between the scalp distributions in this epoch according to lag, but this was not obtained. As a result, strong claims about changes in familiarity with lag cannot be made on the basis of this pattern of outcomes because the statistics do not isolate changes in the ERP effects in this epoch to the locations at which activity has been linked to item familiarity. This null result may reflect, however, the fact that analyses restricted to items attracting correct lag judgments cannot distinguish between processes that predict lag judgments, and those that are correlated with lag: Response and lag are confounded in this contrast. For this reason, a second set of analyses was undertaken, in which words repeated at the same lag were separated according to whether they attracted correct or incorrect recency judgments.

The central findings in this set of analyses are shown in Figure 2 and summarized in Figure 3. The critical contrasts were between ERP old/new effects associated with correct lag judgments for lag 5 and lag 25 items, and incorrect lag judgments for items from both of these lags. Critically, for these incorrect lag judgments, ERPs were formed only for those items attracting lag 15 judgments. These comprise an underestimate for lag 25 items and an overestimate for lag 5 items.

Only activity at frontal locations predicted correct and incorrect lag judgments in the 300-500 msec epoch, whereas the activity predicting lag judgments extended more posteriorly in the $500-800 \mathrm{msec}$ epoch. For the earlier epoch, frontal old/new effects have been interpreted as an index of familiarity, and of particular importance here are findings that this effect varies according to perceived memory strength (Azimian-Faridani \& Wilding, 2006; Woodruff et al., 2006; see also Curran, DeBuse, Woroch, \& Hirshman, 2006; Curran, 2004). Hintzman (2003) has suggested that one of the processes that 
Figure 3. Mean amplitude measures of the ERP old/new effects associated with correct and incorrect lag judgments for lag 5 and lag 25 words. For the 300-500 msec epoch (left-hand side of figure), the amplitudes are collapsed across five frontal sites (F5/F6, F3/F4, and Fz). For the 500-800 msec epoch (right-hand side), the amplitudes are collapsed across the same montage of five frontal sites, as well as five posterior sites (P5/P6, $\mathrm{P} 3 / \mathrm{P} 4$, and $\mathrm{Pz}$ ).

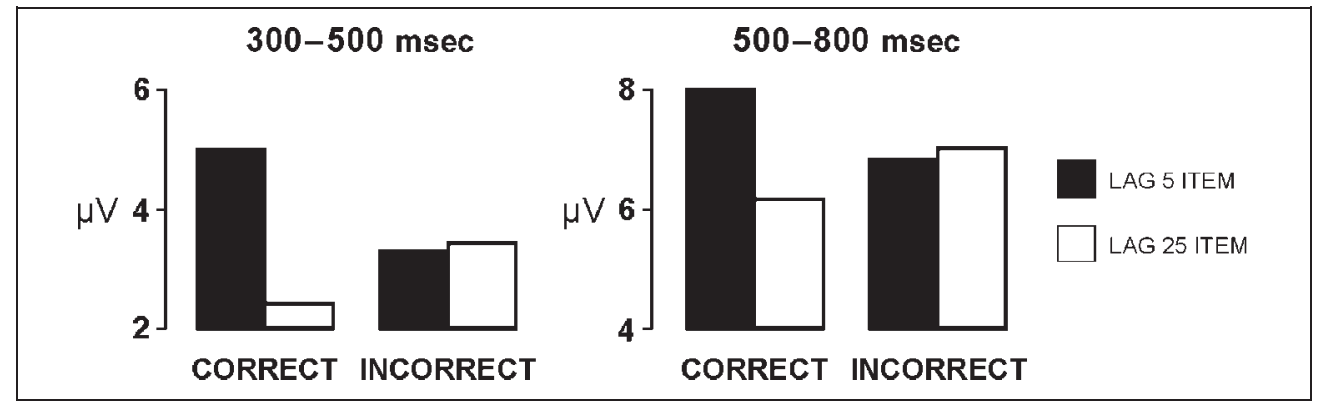

supports recency judgments is the same strength-based process - familiarity - that supports old/new recognition memory judgments, and high levels of familiarity are assumed to accompany more recent events than are low levels of familiarity. If the mid-frontal ERP old/new effect indexes familiarity, then the findings in this experimentan inverse relationship between the magnitude of this effect and the accompanying recency judgment-are consistent with Hintzman's account.

The claim that the mid-frontal old/new effect indexes familiarity has not gone unchallenged, however. According to another interpretation, the effect indexes conceptual priming (Paller, Voss, \& Boehm, 2007; Voss \& Paller, 2006, 2007; Yovel \& Paller, 2004), and the reason the mid-frontal ERP old/new effect varies according to response confidence is because the same processes that contribute to variations in the confidence with which responses are made are also those that introduce variations in the degree of conceptual priming. One means of developing this argument is to claim that, at least under some circumstances, conceptual priming supports familiarity (Paller et al., 2007; Rugg \& Curran, 2007; Yonelinas, 2002). It is not necessary to adopt this position, however: merely noting that there is a degree of correspondence between the factors that induce changes in the two processes is sufficient. From this perspective, the data points in the recency judgment task reported here add to the growing list of manipulations for which the factors influencing familiarity and conceptual priming overlap.

Direct evidence supporting the conceptual priming account would accrue from demonstrations that midfrontal old/new effects are evident when familiarity is equated but conceptual priming varies. Contrary to one recent claim (Voss \& Paller, 2007), ${ }^{2}$ this pattern of data has not been demonstrated. The reverse pattern, by contrast - the presence of mid-frontal ERP old/new effects when conceptual priming is likely to have been constant-has been shown. These data points come from studies incorporating perceptual manipulations of stimuli across study and test phases of retrieval tasks. In at least five studies, the mid-frontal ERP old/new effects for items attracting correct judgments were larger when copy cues were presented at test (Ecker, Zimmer, \& Groh-Bordin, 2007a, 2007b; Groh-Bordin, Zimmer, \& Ecker, 2006; Groh-Bordin, Zimmer, \& Mecklinger, 2005; Schloerscheidt \& Rugg, 2004), and in so far as the meaning of the stimuli is not altered by changes in perceptual format, these findings contradict a conceptual priming account of the mid-frontal ERP old/new effect. The fact that the mid-frontal ERP old/new effect is not always sensitive to study-test overlap (see Introduction) is unsurprising, but the fact that the effect varies according to this manipulation in some circumstances-for example, when test modality or intrinsic versus extrinsic features of a stimulus are manipulated-presents a strong challenge to conceptual priming accounts of the mid-frontal effect (Rugg \& Curran, 2007). The implication of these observations for the current data is that familiarity supports recency judgments, and it does so in a quantitative manner, with the level of familiarity being employed heuristically in order to infer how recently events occurred.

A qualitatively similar interpretation can be applied to the findings in the 500-800 msec epoch, because, as for the earlier time period, larger ERP old/new effects predicted shorter lag judgments. Positive-going ERP old/new effects, often with a left parietal maximum, have been associated with the process of recollection (Wilding \& Sharpe, 2003; Wilding, 2000; Wilding \& Rugg, 1996). This raises the possibility that recollection, in the same way as familiarity, was also employed heuristically in order to support recency judgments. Support for this account comes from findings that the magnitude of the left parietal ERP old/new effect varies according to either the quality or quantity of task-relevant information that is retrieved (Vilberg et al., 2006; Wilding, 2000). It is also important to note that this is not the only way in which the ERP data acquired in this study could have implicated recollection in recency judgments. Another possible outcome was that larger parietal old/new effects would uniformly accompany correct, rather than incorrect, lag judgments (a finding that has been obtained in some experiments where the focus has been on recovery of forms of contextual information other than time; e.g., Wilding, 1999; Wilding \& Rugg, 1996). This outcome 
would have signaled that recollection was employed as a location-based process, whereas the fact that greater relative positivity at parietal locations predicted shorter lag judgments is consistent with the view that recollection was employed as a distance-based process. Whether this claim holds for lags extending beyond the upper bound of 25 intervening items that was employed in this study remains an open question, and the findings in the remember/know study of recency memory reported by Hintzman (2001; see Introduction) predict a greater relative contribution from familiarity as lag increases.

In addition, although this account of the processes supporting recency judgments links performance on these kinds of tasks coherently with the processes of recollection and familiarity (Yonelinas, 1994, 2002), it does not account entirely for the ERP findings in the 500-800 msec epoch. This is because the outcomes of the analyses indicated that activity at anterior as well as at posterior locations contributed equally to recency judgments. The posterior-parietal distribution of the old/new effect that has been linked with recollection (Friedman \& Johnson, 2000) suggests, therefore, that processes other than recollection were engaged in this epoch and contributed to recency judgments.

One possibility is that, rather than indexing, in part, the deployment of recollected information for recency judgments, the diffuse distribution of the activity predicting recency judgments in this epoch is an index of a separate distance-based process that is specific to tasks in which people are prompted to make judgments about when events occurred. A second possibility is that the anterior element of the recency sensitive effect in this epoch indexes a process separate from both the posterior (recollection) effect in this epoch, and the familiarity effect in the earlier epoch. The anterior distribution and time course of the effect would support broadly an interpretation in terms of retrieval control processes, although how that would be linked to the way in which this aspect of the electrical record responded to correct and incorrect judgments at different lags requires consideration.

A third, and perhaps more intriguing, possibility is that the effects in this epoch are a combination of the parietal old/new effect, alongside a continuation of the anteriorly distributed effect that predicted recency judgments in the 300-500 msec epoch. The immediate impediment to this account is the fact that the mid/frontal ERP old/new effect does not typically extend beyond $500 \mathrm{msec}$ (for a recent review, see Curran, Tepe, et al., 2006). One possibility, however, is that the demands of the recency task extended the time course of the mid-frontal ERP old/new effect. This may have occurred if the requirement to make a recency judgment resulted, on average, in somewhat greater attention to and/or a more temporally extended assessment of the information content indexed by the mid-frontal ERP old/new effect than is undertaken typically in tasks requiring only old/new recognition memory judgments.
Evidence in support of this account would stem from demonstrations that the mid-frontal ERP old/new effect is sensitive to different task demands, and there are a minimum of three examples of this kind. First, at least under some circumstances, the mid-frontal ERP old/new effect is smaller in indirect than in direct memory tasks (Groh-Bordin et al., 2005). Second, manipulations of the time between the first and second presentations of test items influence the effect differently across indirect and direct memory tasks (Wolk et al., 2006; Curran \& Friedman, 2004; Rugg, 1990). Third, Ecker, Zimmer, Groh-Bordin, and Mecklinger (2007) have shown that the amplitude of the mid-frontal ERP old/new effect elicited by studied objects on novel backgrounds is larger when people are cued to the location of the object on the background prior to stimulus presentation. This finding implicates the degree to which attention is oriented to task-relevant information as a moderator of the amplitude of the mid-frontal ERP old/new effect (Ecker et al., 2007; Rugg \& Curran, 2007). In combination, these findings emphasize that the mid-frontal ERP old/new effect is sensitive to demands imposed at the time of retrieval. They do not, however, demonstrate that the time course of the mid-frontal ERP old/new effect can be extended as a function of task demands.

It is also worth considering the correspondence between the way in which the mid-frontal ERP old/new effect predicts JORs and the properties of cells identified in single-unit recording studies in the primate (in particular, see Xiang \& Brown, 1998, 2004). Cells that respond differently upon presentation and then re-presentation of stimuli have been described in the temporal lobe as well as in the prefrontal cortex, with the time course of responses for the latter ( $\sim 250 \mathrm{msec}$ poststimulus) bolstering the suggestion that neural activity in the prefrontal cortex is responsible for the mid-frontal old/new effect (Rugg \& Curran, 2007). Subpopulations of these cells in the prefrontal cortex also signal relative recency in so far as their response upon re-presentation declines as the gap between the first and the second presentation increases. If nothing else, these correspondences emphasize that subsequent fMRI studies of recency memory will be important in linking the functional claims made here to questions about the neural substrates in humans that support familiarity and recency judgments. Although recency judgments have been required in some fMRI studies (e.g., Dudukovic \& Wagner, 2007; Rajah \& McIntosh, 2006), in no studies, to our knowledge, have neural signatures associated with under- and overestimates of recency been contrasted. This is the critical novel ERP contrast that we have described here, and which has provided leverage for the functional claims about processes supporting judgments for when events occurred.

In summary, the key findings in this experiment are that: (i) the electrophysiological activity predicting correct and incorrect recency judgments constituted greater relative positivity associated with shorter JORs, and (ii) the 
neural activity predicting JORs was restricted to anterior sites in the 300-500 but not in the 500-800 msec epoch. These data points support strongly the claims that: (i) two distinct distance-based processes support JORs, and (ii)

\section{APPENDIX 1}

Probabilities of Correct Old and New Judgments and Associated Reaction Times (RTs), Separated According to Lag $(n=23)^{\mathrm{a}}$

\begin{tabular}{lcccc}
\hline & New & Lag 5 & Lag 15 & Lag 25 \\
\hline$p($ correct) & $.96(.04)$ & $.90(.08)$ & $.89(.09)$ & $.88(.10)$ \\
RT & $835(144)$ & $975(242)$ & $907(184)$ & $871(145)$ \\
\hline
\end{tabular}

${ }^{\mathrm{a}}$ Standard deviations are in parentheses one of these processes is familiarity. The data are also consistent with the view that recollection contributes to JORs in a distance-based manner, although, as outlined above, competing interpretations remain.

\section{APPENDIX 2}

Probabilities of Each Lag Judgment (Lag 5, Lag 15, Lag 25), Conditional on a Correct Old Judgment and Separated According to Lag $(n=23)^{\mathrm{a}}$

\begin{tabular}{lccc}
\hline & \multicolumn{3}{c}{ Actual Lag } \\
\cline { 2 - 4 } Judgment & $\operatorname{Lag} 5$ & $\operatorname{Lag} 15$ & $\operatorname{Lag} 25$ \\
\hline Lag 5 & $\mathbf{5 5 ( . 1 1 )}$ & $.11(.05)$ & $.05(.04)$ \\
Lag 15 & $.38(.09)$ & $\mathbf{. 6 3 ( . 1 0 )}$ & $.47(.10)$ \\
Lag 25 & $.07(.04)$ & $.26(.10)$ & $\mathbf{. 4 8}(.11)$ \\
\hline
\end{tabular}

${ }^{\mathrm{a}}$ Correct lag judgments are in bold, standard deviations are in parentheses.

\section{APPENDIX 3}

The Outcomes of the Analyses ( $F$ Values and Significance Levels) of the ERP Old/New Effects $(n=23)$ for Words Attracting Correct Old/New and Correct Lag Judgments for the 300-500 and 500-800 msec Epochs ${ }^{\mathrm{a}}$

\begin{tabular}{|c|c|c|c|c|c|c|}
\hline & \multicolumn{3}{|c|}{$300-500 \mathrm{msec}$} & \multicolumn{3}{|c|}{$500-800 \mathrm{msec}$} \\
\hline & $\operatorname{Lag} 5$ & $\operatorname{Lag} 15$ & $\operatorname{Lag} 25$ & $\operatorname{Lag} 5$ & $\operatorname{Lag} 15$ & $\operatorname{Lag} 25$ \\
\hline CC $(1,22)$ & $115.21 * * * *$ & $61.59 * * * *$ & $15.67 * * *$ & $63.73^{* * * *}$ & $47.83^{* * * *}$ & $25.30 * * * *$ \\
\hline $\mathrm{CC} \times \mathrm{AP}(1,22)$ & $5.31 * *$ & $3.07 *$ & - & $7.35 * *$ & $5.72 * *$ & $10.25 * * *$ \\
\hline $\mathrm{CC} \times \mathrm{ST}(4,88)$ & $13.63 * * * *(.59)$ & $2.53 *(.60)$ & $2.72 *(.50)$ & $2.69 *(.64)$ & - & - \\
\hline $\mathrm{CC} \times \mathrm{AP} \times \mathrm{ST}(4,88)$ & $4.26 * * *(.73)$ & $2.28 *(.65)$ & - & $4.81 * *(.44)$ & $3.95 * *(.44)$ & - \\
\hline
\end{tabular}

Full degrees of freedom are shown on LHS, with epsilon values in parentheses.

${ }^{\mathrm{a}}$ The factors are response category (CC), anterior-posterior dimension (AP), and site (ST).

$* p<.1$

$* * p<.05$

$* * * p<.01$

$* * * * p<.001$.

\section{Acknowledgments}

This work was supported by the UK BBSRC and the MRC.

Reprint requests should be sent to Kerrie L. Grove, Cardiff University Brain Research Imaging Centre (CUBRIC), School of Psychology, Cardiff University, Cardiff, CF10 3AT, Wales, UK, or via e-mail: grovekl@cardiff.ac.uk.

\section{Notes}

1. In this and all subsequent repeated measures ANOVAs, the Geisser-Greenhouse correction was employed where appropriate (Winer, 1971; Greenhouse \& Geisser, 1959). Corrected degrees of freedom are shown in the text. In the tables, full $d f \mathrm{~s}$ for each contrast are shown on the left-hand side, with the epsilon correction value in parentheses alongside each relevant $F$ value.
2. Voss and Paller (2007) separated two classes of stimuli according to the degree of conceptual priming associated with them, and in the 300-500 msec time window, the ERPs at anterior locations were more positive-going for the class of stimuli associated with the greater degree of conceptual priming. In a memory test, remember/know judgments were made to each of the stimuli, and the authors claimed that the overall familiarity of the items entering into the high and low conceptual priming categories was equal. The basis for this claim was that know judgments provided an index of familiarity, and there was no reliable difference in the likelihood of items from each class attracting a know judgment. This claim is undermined by two observations. First, the authors did not report remember/know false alarm rates for unstudied items associated with different levels of conceptual priming. Second, the probability of a remember judgment was markedly higher for items associated with the high conceptual priming category. This means that, for the proportions of items in the high 
and low conceptual priming categories that did not attract a remember response, the likelihood of a know response was markedly higher in the former than in the latter. The most straightforward means of explaining this pattern is to assume that, on average, the level of familiarity associated with the high conceptual priming stimulus class was greater than that associated with the low conceptual priming class.

\section{REFERENCES}

Allan, K., Wilding, E. L., \& Rugg, M. D. (1998).

Electrophysiological evidence for dissociable processes contributing to recollection. Acta Psychologica, 98, 231-252.

Azimian-Faridani, N., \& Wilding, E. L. (2006). The influence of criterion shifts on electrophysiological correlates of recognition memory. Journal of Cognitive Neuroscience, 18, 1075-1086.

Bridson, N. C., Fraser, C. S., Herron, J. E., \& Wilding, E. L. (2006). Electrophysiological correlates of familiarity in recognition memory and exclusion tasks. Brain Research, 1114, 149-160.

Brown, N. R., Rips, L. J., \& Shevell, S. K. (1985). The subjective dates of natural events in very long-term memory. Cognitive Psychology, 17, 139-177.

Curran, T. (1999). The electrophysiology of incidental and intentional retrieval: ERP old/new effects in lexical decision and recognition memory. Neuropsychologia, 37, 771-785.

Curran, T. (2000). Brain potentials of recollection and familiarity. Memory \& Cognition, 28, 923-938.

Curran, T. (2004). Effects of attention and confidence on the hypothesized ERP correlates of recollection and familiarity. Neuropsychologia, 42, 1088-1106.

Curran, T., \& Cleary, A. M. (2003). Using ERPs to dissociate familiarity from recollection in picture recognition. Cognitive Brain Research, 15, 191-205.

Curran, T., DeBuse, C., Woroch, B., \& Hirshman, E. (2006). Combined pharmacological and electrophysiological dissociation of familiarity and recollection. Journal of Neuroscience, 26, 1979-1985.

Curran, T., \& Friedman, W. J. (2003). Differentiating location- and distance-based processes in memory for time: An ERP study. Psychonomic Bulletin \& Review, 10, 711-717.

Curran, T., \& Friedman, W. J. (2004). ERP old/new effects at different retention intervals in recency discrimination tasks. Cognitive Brain Research, 18, 107-120.

Curran, T., Tanaka, J. W., \& Weiskopf, D. M. (2002). An electrophysiological comparison of visual categorization and recognition memory. Cognitive, Affective, \& Behavioral Neuroscience, 2, 1-18.

Curran, T., Tepe, K. L., \& Piatt, C. (2006). ERP explorations of dual processes in recognition memory. In H. D. Zimmer, A. Mecklinger, \& U. Lindenberger (Eds.), Binding in buman memory: A neurocognitive approach (pp. 139-179). Oxford: Oxford University Press.

Dudukovic, N. M., \& Wagner, A. D. (2007). Goal-dependent modulation of declarative memory: Neural correlates of temporal recency decisions and novelty detection. Neuropsychologia, 45, 2608-2620.

Duzel, E., Vargha-Khadem, F., Heinze, H. J., \& Mishkin, M. (2001). Brain activity evidence for recognition without recollection after early hippocampal damage. Proceedings of the National Academy of Sciences, U.S.A., 98, 8101-8106.

Duzel, E., Yonelinas, A. P., Mangun, G. R., Heinze, H. J., \& Tulving, E. (1997). Event-related brain potential correlates of two states of conscious awareness in memory. Proceedings of the National Academy of Sciences, U.S.A., 94, 5973-5978.
Ecker, U. K. H., Zimmer, H. D., \& Groh-Bordin, C. (2007a). Color and context: An ERP study on intrinsic and extrinsic feature binding in episodic memory. Memory \& Cognition, 35, 1483-1501.

Ecker, U. K. H., Zimmer, H. D., \& Groh-Bordin, C. (2007b). The influence of object and background colour manipulations on the electrophysiological indices of recognition memory. Brain Research, 1185, 221-230.

Ecker, U. K. H., Zimmer, H. D., Groh-Bordin, C., \& Mecklinger, A. (2007). Context effects on familiarity are familiarity effects of context-An electrophysiological study. International Journal of Psychophysiology, 64, 146-156.

Friedman, D. (1990a). Cognitive event-related potential components during continuous recognition memory for pictures. Psychophysiology, 27, 136-148.

Friedman, D. (1990b). Endogenous event-related brain potentials during continuous recognition memory for words. Biological Psychology, 30, 61-87.

Friedman, D., \& Johnson, R. (2000). Event-related potential (ERP) studies of memory encoding and retrieval: A selective review. Microscopy Research and Techniques, 51, 6-28.

Friedman, W. J. (1993). Memory for the time of past events. Psychological Bulletin, 113, 44-66.

Friedman, W. J. (1996). Distance and location processes in memory for the times of past events. In D. L. Medin (Ed.), The psychology of learning and motivation (pp. 1-41). San Diego: Academic Press.

Friedman, W. J. (2001). Memory processes underlying humans' chronological sense of the past. In C. Hoerl \& T. McCormack (Eds.), Time and memory: Issues in philosophy and psychology (pp. 139-167). Oxford: Clarendon Press.

Greenhouse, G. W., \& Geisser, S. (1959). On methods in the analysis of profile data. Psychometrika, 49, 95-112.

Groh-Bordin, C., Zimmer, H. D., \& Ecker, U. K. H. (2006). Has the butcher on the bus dyed his hair? When color changes modulate ERP correlates of familiarity and recollection. Neuroimage, 32, 1879-1890.

Groh-Bordin, C., Zimmer, H. D., \& Mecklinger, A. (2005). Feature binding in perceptual priming and in episodic object recognition: Evidence from event-related brain potentials. Cognitive Brain Research, 24, 556-567.

Hinrichs, J. V. (1970). A two-process memory-strength theory for judgment of recency. Psychological Review, 77, 223-233.

Hinrichs, J. V., \& Buschke, H. (1968). Judgment of recency under steady state conditions. Journal of Experimental Psychology, 78, 574-579.

Hintzman, D. L. (2001). Judgments of frequency and recency: How they relate to reports of subjective awareness. Journal of Experimental Psychology: Learning, Memory, and Cognition, 27, 1347-1358.

Hintzman, D. L. (2003). Judgments of recency and their relation to recognition memory. Memory \& Cognition, 31, 26-34.

Hintzman, D. L. (2004). Time versus items in judgment of recency. Memory \& Cognition, 32, 1298-1304.

Hintzman, D. L. (2005). Memory strength and recency judgments. Psychonomic Bulletin \& Review, 12, 858-864.

Hintzman, D. L., Caulton, D. A., \& Levitin, D. (1998). Retrieval dynamics in recognition and list discrimination: Further evidence of separate processes of familiarity and recall. Memory \& Cognition, 26, 449-462.

Hintzman, D. L., \& Curran, T. (1994). Retrieval dynamics of recognition memory and frequency judgments: Evidence for separate processes of familiarity and recall. Journal of Memory and Language, 33, 1-18.

Jacoby, L. L., \& Dallas, M. (1981). On the relationship between autobiographical memory and perceptual learning. Journal of Experimental Psychology: General, 3, 306-340. 
Jacoby, L. L., \& Kelley, C. (1992). Unconscious influences of memory: Dissociations and automaticity. In A. D. Milner \& M. D. Rugg (Eds.), The neuropsychology of consciousness (pp. 201-233). London: Academic Press.

Jasper, H. A. (1958). The ten-twenty system of the international federation. Electroencephalography and Clinical Neurophysiology, 10, 371-375.

McCarthy, G., \& Wood, C. C. (1985). Scalp distributions of event-related potentials: An ambiguity associated with analysis of variance models. Electroencephalography and Clinical Neurophysiology, 62, 203-208.

Mecklinger, A. (2000). Interfacing mind and brain: A neurocognitive model of recognition memory. Psychophysiology, 37, 565-582.

Mecklinger, A., von Cramon, D. Y., \& Matthes-von Cramon, G. (1998). Event-related potential evidence for a specific recognition memory deficit in adult survivors of cerebral hypoxia. Brain, 121, 1919-1935.

Nessler, D., \& Mecklinger, A. (2003). ERP correlates of true and false recognition after different retention delays: Stimulus- and response-related processes. Psychophysiology, 40, 146-159.

Nessler, D., Mecklinger, A., \& Penney, T. B. (2001). Event related brain potentials and illusory memories: The effects of differential encoding. Cognitive Brain Research, 10, 283-301.

Paller, K. A., Voss, J. L., \& Boehm, S. G. (2007). Validating neural correlates of familiarity. Trends in Cognitive Sciences, 11, 243-250.

Penney, T. B., Mecklinger, A., \& Nessler, D. (2001). Repetition related ERP effects in a visual object target detection task. Cognitive Brain Research, 10, 239-250.

Rajah, M. N., \& McIntosh, A. R. (2006). Dissociating prefrontal contributions during a recency memory task.

Neuropsychologia, 44, 350-364.

Rugg, M. D. (1990). Event-related brain potentials dissociate repetition effects of high and low frequency words. Memory E Cognition, 18, 367-379.

Rugg, M. D. (1994). Event-related potential studies of human memory. In M. S. Gazzaniga (Ed.), The cognitive neurosciences (pp. 789-801). Massachusetts: MIT Press.

Rugg, M. D. (2004). Retrieval processing in human memory: Electrophysiological and fMRI evidence. In M. S. Gazzaniga (Ed.), The new cognitive neurosciences (pp. 727-737). Massachusetts: MIT Press.

Rugg, M. D., \& Curran, T. (2007). Event-related potentials and recognition memory. Trends in Cognitive Sciences, 11, 251-257.

Rugg, M. D., \& Nagy, M. E. (1989). Event-related potentials and recognition memory for words. Electroencephalography and Clinical Neurophysiology, 72, 395-406.

Schloerscheidt, A. M., \& Rugg, M. D. (2004). The impact of change in stimulus format on the electrophysiological indices of recognition. Neuropsychologia, 42, 451-466.

Semlitsch, H. V., Anderer, P., Schuster, P., \& Presslich, O. (1986). A solution for reliable and valid reduction of ocular artifacts, applied to the P300 ERP. Psychophysiology, 23, 695-703.

Smith, M. E. (1993). Neurophysiological manifestations of recollective experience during recognition memory judgements. Journal of Cognitive Neuroscience, 5, 1-13.

Smith, M. E., \& Halgren, E. (1989). Dissociation of recognition memory components following temporal lobe lesions. Journal of Experimental Psychology: Learning, Memory, and Cognition, 15, 50-60.

Tendolkar, I., Schoenfeld, A., Golz, G., Fernandez, G., Kuhl, K., Ferszt, R., et al. (1999). Neural correlates of recognition memory with and without recollection in patients with Alzheimer's disease and healthy controls. Neuroscience Letters, 263, 45-48.
Tulving, E. (1983). Elements of episodic memory. Oxford: Oxford University Press.

Tulving, E. (2002). Episodic memory: From mind to brain Annual Review of Psychology, 53, 1-25.

Vilberg, K. L., Moosavi, R. F., \& Rugg, M. D. (2006). The relationship between electrophysiological correlates of recollection and the amount of information retrieved. Brain Research, 1122, 161-170.

Voss, J. L., \& Paller, K. A. (2006). Fluent conceptual processing and explicit memory for faces are electrophysiologically distinct. Journal of Neuroscience, 26, 926-933.

Voss, J. L., \& Paller, K. A. (2007). Neural correlates of conceptual implicit memory and their contamination of putative neural correlates of explicit memory. Learning and Memory, 14, 259-267.

Wastell, D. G. (1979). The application of low-pass linear filters to evoked potential data: Filtering without phase distortion. Electroencephalography and Clinical Neurophysiology, 46, 355-356.

Wells, J. E. (1974). Strength theory and judgments of frequency and recency. Journal of Verbal Learning and Verbal Behaviour, 13, 378-392.

Wilding, E. L. (1999). Separating retrieval strategies from retrieval success: An event-related potential study of source memory. Neuropsychologia, 37, 441-454.

Wilding, E. L. (2000). In what way does the parietal ERP old/ new effect index recollection? International Journal of Psychophysiology, 35, 81-87.

Wilding, E. L., \& Rugg, M. D. (1996). An event-related potential study of recognition memory with and without retrieval of source. Brain, 119, 889-905.

Wilding, E. L., \& Sharpe, H. (2003). Episodic memory encoding and retrieval: Recent insights from event-related potentials. In A. Zani \& A. Mado-Proverbio (Eds.), The cognitive electrophysiology of mind and brain (pp. 169-196). San Diego: Academic Press.

Winer, B. J. (1971). Statistical principles in experimental design. New York: McGraw-Hill.

Wolk, D. A., Schacter, D. L., Lygizos, M., Mandu Sen, N., Holcomb, P. J., Daffner, K. R., et al. (2006). ERP correlates of recognition memory: Effects of retention interval and false alarms. Brain Research, 1096, 148-162.

Woodruff, C. C., Hyama, H. R., \& Rugg, M. D. (2006). Electrophysiological dissociation of the neural correlates of recollection and familiarity. Brain Research, 1100, 125-135.

Xiang, J. Z., \& Brown, M. W. (1998). Differential neuronal encoding of novelty, familiarity and recency in regions of the anterior temporal lobe. Neuropharmacology, 37, 657-676.

Xiang, J. Z., \& Brown, M. W. (2004). Neuronal responses related to long-term recognition memory process in the prefrontal cortex. Neuron, 42, 817-829.

Yonelinas, A. P. (1994). Receiver-operating characteristics in recognition memory: Evidence for a dual-process model. Journal of Experimental Psychology: Learning, Memory, and Cognition, 20, 1341-1354.

Yonelinas, A. P. (2002). The nature of recollection and familiarity: A review of the 30 years of research. Journal of Memory and Language, 46, 441-517.

Yonelinas, A. P., \& Jacoby, L. L. (1995). The relationship between remembering and knowing as bases for recognition: Effects of size congruency. Journal of Memory and Language, 34, 622-643.

Yovel, G., \& Paller, K. A. (2004). The neural basis of the butcher-on-the-bus phenomenon: When a face seems familiar but is not remembered. Neuroimage, 21, 789-800. 